\title{
MICROBIAL CONTAMINATION OF INDIAN CURRENCY NOTES IN BHOPAL
}

Kalpana Sadawarte ${ }^{1}$, Hemant Mahobe ${ }^{2}$, Gaurav Saxena ${ }^{3}$

\section{HOW TO CITE THIS ARTICLE:}

Kalpana Sadawarte, Hemant Mahobe, Gaurav Saxena. "Microbial Contamination of Indian Currency Notes in Bhopal". Journal of Evolution of Medical and Dental Sciences 2014; Vol. 3, Issue 06, February 10; Page: 13791384, DOI: $10.14260 /$ jemds/2014/1995

ABSTRACT: BACKGROUND: Paper currency notes which are transferred from one individual to other are known to carry micro-organisms on their surface. Currency contaminated by microbes might also act as fomite, playing an important role in the transmission of microorganisms. The handling of contaminated currency may lead to severe infections. AIM: To isolate and identify microorganisms contaminating Indian Currency Notes. METHODS: 180 Indian currency notes including each of INR. (Indian rupee) 5, INR.10, INR.20, INR.50, INR.100 and INR.500 denominations, were collected from peoples of various social strata from different parts of Bhopal. Sterile cotton swab dipped in $1 \%$ peptone water was used for taking swab samples which were inoculated in BHI broth. After that, cultured broth was subcultured on simple and selective media subsequently. On the basis of Gram reaction, colony morphology and standard biochemical reactions, the isolates were identified upto species level. ${ }^{2}$ RESULTS: Among the total 180 Indian currency notes 169 (93.89\%) were contaminated, both with pathogenic and non-pathogenic organisms. From the 312 isolates twelve different types of microorganisms were obtained viz., Bacillus spps (149), S. aureus (53), CONS (Coagulase negative staphylococcus) (27), Micrococcus (31), E.coli (22), Klebsiella spps (8), Pseudomonas aeruginosa (5), Proteus mirabilis (4), Nonfermentors (5), Candida spps (3), Acinetobacter (3) \& Enterococcus (2). Out of 312 total isolates 74 (23.72\%), 92 (29.49\%) \& 146 $(46.79 \%)$ isolates were isolated from Good (new and clean), Average (soiled) \& Poor (tattered and dirty) condition notes respectively. CONCLUSIONS: From the present study it was concluded that Indian currency notes are commonly contaminated by pathogenic and non-pathogenic organisms that represents risks and public health hazards to the individuals and community as a whole.

KEYWORDS: Microbial contamination, Currency notes, Pathogenic microorganisms

INTRODUCTION: Microorganisms are found almost everywhere in our environment. Some microorganisms are useful but some are pathogenic. Microorganisms are known to spread via air, water, and food etc., an important mechanism of the spread of pathogens is by formites. ${ }^{1}$ Fomites or inanimate objects play a major role in indirect transmission of infections like diphtheria, trachoma, gastroenteritis, whooping cough and pathogenic agents causing diarrhoea. Currency contaminated by microbes might also act as fomites, playing an important role in the transmission of microorganisms. ${ }^{2}$ Currency notes are used as a medium for exchange for goods and services, settlement of debts and for deferred payments in economic activities.

The contamination of the notes could also be from several sources; it could be from the atmosphere, during storage, usage, handling or production. ${ }^{3}$ Paper Currency, can be contaminated by droplets during coughing, sneezing, touching with previously contaminated hands or other materials and placement on dirty surface. Many people tongue-wet their fingers when counting money thereby, contaminating their fingers as well as currency notes. So, it is obvious that anything that gets on hands may be transferred to money and vice-versa. ${ }^{4}$ Paper currency is commonly handled by various 
categories of people during transaction. ${ }^{5}$ Pathogenic microorganisms that may survive on the currency notes may serve as potential sources of enteropathogens that cause infections and potential sporadic cases of food borne diseases. ${ }^{6}$ Money is handled by persons of varying health and hygienic standards and is stored under varying environmental and personal hygienic conditions. Lowerdenomination notes receive the most handling because they are exchanged more often. Money may serve as an unrecognized reservoir for pathogenic and non-pathogenic bacteria. ${ }^{7}$

Various microorganisms have been isolated from money worldwide including developed countries. Bacillus spp. and Staphylococcus aureus have been identified as common contaminants isolated from paper currency. However, other organisms like, Micrococcus spp, Corynebacterium spp, Vibrio cholerae, Mycobacterium tuberculosis and members of the family Enterobacteriaceae have been isolated from currency too. The pathogenic or potentially pathogenic bacteria found on these currency notes may cause a wide variety of diseases from food poisoning, wound and skin infections, respiratory and gastrointestinal problems to life threatening diseases such as meningitis and septicemia. ${ }^{8}$ Microbial contamination of paper money is not only confined to developing nations. Several studies from United States reported contamination of coins and paper bills and the identification revealed the presence of pathogenic microbes.9,10 This study was aimed to determine the level of bacterial contamination of the Indian currency notes by microbial pathogens and to identify the possible associated risk factors.

\section{MATERIALS AND METHODS:}

\section{Sample collection and transport:}

The study was conducted from July to September 2013. A total of 180 Indian currency notes consisting each of INR.5, INR.10, INR.20, INR.50, INR.100 and INR.500 denominations, was collected from peoples of various social strata from different parts of Bhopal from their work places (i.e., vendors like fish, meat, fruits, vegetables vendors, Tempo drivers, Washer man, restaurants, banks, hospital billing counter, laboratory workers, medical students and faculties) in Bhopal city, MP, India.

These currency notes were divided into two groups based on lower (INR.5, INR.10 \& INR.20) and higher (INR.50, INR.100 \& INR.500) denomination and these were further divided according to their conditions, Good (new and clean), Average (soiled) \& Poor (tattered and dirty) note. The higher and lower denomination currency note samples were 30 each, 10 samples of each from good, average \& poor condition notes.

Each currency note was collected in sterile plastic bag and transported to Microbiology Laboratory in the Department of Microbiology, Peoples College of Medical Science \& Research Centre, Bhopal, India for further analysis. ${ }^{3}$

\section{Bacterial isolation and identification: ${ }^{2,10}$}

The samples from each currency notes were collected with sterile cotton swab dipped in 1\% peptone water and were used for taking samples. Swabbing was done from each corner and central parts from both sides of currency notes. The swab samples were carried to laboratory for further microbiological analysis. These swabs were also inoculated into the BHI broth. Inoculated BHI broths were incubated at $37^{\circ} \mathrm{C}$ for $24 \mathrm{~h}$, after which $50 \mu \mathrm{l}$ of the BHI broth was subcultured onto solid media like Blood agar and Mac-Conkey's agar plates simultaneously. The inoculated media were incubated aerobically at $35-37^{\circ} \mathrm{C}$ for 24 hours and then examined for bacterial growth according to standard 
microbiological technique. According to colony morphology and Gram staining it were plated on selective media such as Eosin Methylene Blue Agar, Mannitol salt agar, Baird parker agar, Alkaline peptone water, TCBS agar, Selenite-F broth, Salmonella Shigella agar, Xylose lysine deoxycholate agar, Cetrimide agar, Bismuth sulfite agar. ${ }^{10}$

RESULTS: Total 180 Indian currency notes were collected and included in the study, among those 169 (93.89\%) were contaminated, both with pathogenic and non-pathogenic organisms. Eleven of the currency notes which appeared new and clean did not grow any micro-organism. From the culture of these 180 currency notes, 312 isolates of twelve different types of microorganisms were obtained viz., Bacillus spps (82.8\%) S. aureus (29.5\%), CONS (15\%), Micrococcus (17.2\%), E.coli (12.2\%), Klebsiella spps (4.44\%), Pseudomonas aeruginosa (2.78\%), Proteus mirabilis (2.22\%), Nonfermentors (2.78\%), Candida spps (1.67\%), Acinetobacter (1.67\%), Enterococcus (1.11\%). (Table: 1) Out of 312 total isolates 177 (56.73\%) and 135 (43.26\%) were obtained from Lower \& Higher denomination currency respectively. (Table: 2) and 74 (23.72\%), 92 (29.49\%) \& 146 $(46.79 \%)$ isolates were isolated from good, average \& poor condition notes respectively. (Table: 3 )

DISCUSSION: In day to day use paper currency notes are transferred from one individual to another which transmits the microorganisms present on paper currency notes. In India even paper currency notes are poorly-handled. The major population of India do not carry money in wallets and squeezing of currency notes is a common occurrence. In the present study most of the currency notes were contaminated by Bacillus spps. and S.aureus. The lower denomination currency notes are frequently circulated for daily activities where notes get tattered and dirty, therefore become more contaminated. Currency notes of both lower and higher denomination which were in poor conditions were more contaminated than notes those which were in good condition.

A study done by Ahmed et al., (2010) in Bangladesh suggested that the paper currency notes were commonly contaminated with pathogenic microorganisms and this contamination played a significant role in the transmission of potentially harmful microorganisms for different diseases. ${ }^{10}$ In this study, along with the non-pathogenic microorganisms, many pathogenic organisms such as $\mathrm{S}$. aureus, E.coli, Klebsiella spps, Pseudomonas aeruginosa, Proteus mirabilis, Nonfermentors, Candida spps, Acinetobacter spp \& Enterococcus spp were also isolated. Non-pathogenic organisms may also cause diseases in immunocompromised people.

Feglo P and Nkansah M concluded in their study that a total of 70 Ghanaian currency notes were analyzed for bacterial contamination. 112 different bacteria were isolated from 69 currency notes and one did not grow any bacterium, giving percentage of contamination to be $98.57 \% .{ }^{11}$ Study carried out by Pal K et al., (2013) showed that $91 \%$ of currencies were contaminated with pathogenic organisms. ${ }^{4}$ In our study, we found that $93.89 \%$ currency notes were contaminated, both with pathogenic and non-pathogenic organisms.

Pradeep NV et al., (2012) carried out similar study, in which all the currency notes were contaminated with microorganisms. Bacterial concentration was found to be high in butcher and municipal corporation samples when compared to bank samples. ${ }^{12} \mathrm{We}$ also found that currency notes collected from lower socio-economic peoples which were in poor condition were more contaminated. 
CONCLUSION: From the present study it is concluded that Indian currency notes are commonly contaminated from pathogenic and non-pathogenic organisms that represents risks and public health hazards to the community and individuals. Thus individuals should improve upon their personal health consciousness by washing their hands regularly after handling of currency notes, prevent babies from handling currency notes and avoid the use of saliva during counting of currency notes as well as desist from placing money in the mouth, sticking currency notes in brassieres and biting off corners of banknotes. ${ }^{6}$ Currency notes must be handled with caution and great care especially during the preparation and handling of food to avoid contamination. Personal hygiene is recommended especially to those who handle food and money simultaneously. ${ }^{13}$ There should be public awareness of the fact that currency notes could be a source of infection and dangerous to health. ${ }^{1}$

It is recommended that dirty and tattered notes should be deposited in the bank and discarded by the banks. Reserve Bank of India should also launch washable and durable plastic currency notes.

\section{REFERENCES:}

1. Barolia SK, Verma S, Verma BK. Coliform Contamination on different Paper Currency in Ajmer, Rajasthan, India. Universal Journal of Environmental Research and Technology, 2011; 1 (4): 552-556.

2. Sharma A, Dhanashree B. Screening of currency in circulation for bacterial contamination. Current Science 2011; $100(6)$.

3. Neel R. Multidrug Resistance of Isolates of Methicillin Resistant Staphylococcus Aureus (MRSA) In Paper Currency Notes From Restaurants And Hotels In Lusaka In Zambia. Int J Pharm Sci, 2012; 5(1): 363-366.

4. Pal K, Das NS, Bhattacharya S. Bacteriological profile of Indian currency circulating in a tertiary care hospital in rural Bengal. IJRRMS 2013:3(2)

5. Neel R. Isolation of pathogenic microorganisms from contaminated paper currency notes in circulation from different market places in Korogwe and Mombo towns in Tanzania. J. Microbiol Biotech. Res, 2012, 2 (3):470-474.

6. Tagoe DNA, Adams L, Kangah, VG. Antibiotic Resistant Bacterial Contamination of the Ghanaian Currency Note: A Potential Health Problem. J Microbiol Biotech Res. 2011; 1(4):37-44.

7. Al-Ghamdi AK, Abdelmalek SM, Bamaga MS, et al. Bacterial contamination of Saudi "one" Riyal paper notes. Southeast Asian J Trop Med Public Health 2011; 42(3):711-6.

8. Elumalai EK, David E, Hemachandran J. Bacterial contamination of Indian currency notes (rupee). The International Journal of Occupational and Environmental Medicine 2012; 3:204205.

9. Rafiq Khan M, Venkatesh RK, Ravi N, Ravikumar R, Kumar S. Assessment of Microbial Contamination of Indian Paper Currency Notes in Circulation. International Journal of Recent Scientific Research, 2013; 4(10): 1516-1518.

10. Ahmed MSU, Parveen S, Nasreen T, Feroza B. Evaluation of microbial contamination of Bangladesh paper currency notes (Taka) in circulation. Adv Biol Res. 2010; 4: 266-271.

11. Feglo P, Nkansah M. Bacterial load on Ghanaian currency notes. Afr J Microbiol Res 2010; 4(22): 2375-2380. 
12. Pradeep NV et, al. Microbial contamination of Indian currency notes in circulation. JRB 2012; 2(4): 377-382.

13. Sabahat $S$, Humaira R. Evaluation of bacterial contamination of Pakistani paper currency notes (rupee) in circulation in Karachi. European Journal of Biological Sciences.2011; 3(3):94-8.

\begin{tabular}{|c|c|c|}
\hline Microorganism & No. & $\%$ \\
\hline Bacillus spps & 149 & 82.8 \\
\hline Staphylococcus aureus & 53 & 29.5 \\
\hline CONS & 27 & 15 \\
\hline Micrococcus & 31 & 17.2 \\
\hline Escherichia coli & 22 & 12.2 \\
\hline Klebsiella spps & 08 & 4.44 \\
\hline Pseudomonas aeruginosa & 05 & 2.78 \\
\hline Proteus mirabilis & 04 & 2.22 \\
\hline Nonfermentors & 05 & 2.78 \\
\hline Acinetobacter spps & 03 & 1.67 \\
\hline Enterococcus spps & 02 & 1.67 \\
\hline Candida spps & 03 & 1.11 \\
\hline Total & 312 & 100 \\
\hline
\end{tabular}

Table 1: Number and percentage of micro-organisms isolated from Indian Currency Notes

\begin{tabular}{|c|c|c|c|c|c|c|c|c|c|c|c|c|c|c|c|c|c|c|c|}
\hline \multirow{3}{*}{ Organism $\downarrow$} & \multicolumn{9}{|c|}{ Lower Denomination Currency } & \multicolumn{9}{|c|}{ Higher Denomination Currency } & \multirow{3}{*}{ Total } \\
\hline & \multicolumn{3}{|c|}{ INR.5 } & \multicolumn{3}{|c|}{ INR.10 } & \multicolumn{3}{|c|}{ INR.20 } & \multicolumn{3}{|c|}{ INR.50 } & \multicolumn{3}{|c|}{ INR.100 } & \multicolumn{3}{|c|}{ INR.500 } & \\
\hline & $\mathbf{G}$ & $\mathbf{A}$ & $\mathbf{P}$ & $\mathbf{G}$ & $\mathbf{A}$ & $\mathbf{P}$ & $\mathbf{G}$ & $\mathbf{A}$ & $\mathbf{P}$ & G & $\mathbf{A}$ & $\mathbf{P}$ & $\mathbf{G}$ & $\mathbf{A}$ & $\mathbf{P}$ & $\mathbf{G}$ & $\mathbf{A}$ & $\mathbf{P}$ & \\
\hline Bacillus spps & 8 & 9 & 9 & 8 & 8 & 10 & 8 & 9 & 9 & 8 & 8 & 8 & 7 & 7 & 9 & 8 & 7 & 9 & 149 \\
\hline S.aureus & 2 & 3 & 5 & 2 & 3 & 5 & 3 & 3 & 6 & 3 & 2 & 3 & 2 & 2 & 3 & 2 & 1 & 3 & 53 \\
\hline CONS & 2 & 2 & 3 & 0 & 1 & 3 & 1 & 2 & 2 & 1 & 1 & 2 & 1 & 2 & 2 & 0 & 1 & 1 & 27 \\
\hline Micrococcus & 2 & 3 & 4 & 1 & 2 & 4 & 1 & 0 & 3 & 0 & 1 & 2 & 0 & 2 & 1 & 1 & 2 & 2 & 31 \\
\hline E.coli & 1 & 1 & 3 & 0 & 1 & 3 & 0 & 1 & 2 & 0 & 1 & 3 & 0 & 1 & 2 & 0 & 1 & 2 & 22 \\
\hline Klebsiella spps & 0 & 0 & 2 & 0 & 0 & 1 & 0 & 1 & 0 & 0 & 0 & 2 & 0 & 0 & 1 & 0 & 0 & 1 & 08 \\
\hline P.aeruginosa & 1 & 0 & 0 & 0 & 0 & 1 & 0 & 0 & 1 & 0 & 0 & 1 & 0 & 0 & 1 & 0 & 0 & 0 & 05 \\
\hline P.mirabilis & 0 & 0 & 1 & 0 & 1 & 1 & 0 & 0 & 1 & 0 & 0 & 0 & 0 & 0 & 0 & 0 & 0 & 0 & 04 \\
\hline Non fermenter & 0 & 0 & 2 & 0 & 0 & 1 & 0 & 0 & 0 & 0 & 0 & 0 & 1 & 0 & 0 & 0 & 1 & 0 & 05 \\
\hline Acienatobacter & 0 & 0 & 1 & 0 & 0 & 1 & 0 & 0 & 0 & 0 & 0 & 0 & 0 & 0 & 1 & 0 & 0 & 0 & 03 \\
\hline Enterococcus & 0 & 0 & 1 & 0 & 0 & 0 & 0 & 0 & 0 & 0 & 1 & 0 & 0 & 0 & 0 & 0 & 0 & 0 & 02 \\
\hline Candida spps & 0 & 0 & 1 & 0 & 0 & 0 & 0 & 1 & 0 & 0 & 0 & 0 & 0 & 0 & 1 & 0 & 0 & 0 & 03 \\
\hline \multirow{3}{*}{ Total } & 16 & 18 & 32 & 11 & 16 & 30 & 13 & 17 & 24 & 12 & 14 & 21 & 11 & 14 & 21 & 11 & 13 & 18 & \multirow{3}{*}{312} \\
\hline & & 66 & & & 57 & & & 54 & & & 47 & & & 46 & & & 42 & & \\
\hline & \multicolumn{9}{|c|}{177} & \multicolumn{9}{|c|}{135} & \\
\hline
\end{tabular}

Table 2: Distribution of micro-organisms according to denomination of currency notes 


\begin{tabular}{|c|c|c|c|c|}
\hline \multirow{2}{*}{ Microorganism } & \multicolumn{3}{|c|}{ Condition of Currency Notes } & \multirow{2}{*}{ Total } \\
\hline & $\mathbf{G}$ & $\mathbf{A}$ & $\mathbf{P}$ & \\
\hline Bacillus spps & 47 & 48 & 54 & 149 \\
\hline Staphylococcus aureus & 14 & 14 & 25 & 53 \\
\hline CONS & 05 & 09 & 13 & 27 \\
\hline Micrococcus & 05 & 10 & 16 & 31 \\
\hline Escherichia coli & 01 & 06 & 15 & 22 \\
\hline Klebsiella spps & 0 & 01 & 07 & 08 \\
\hline Pseudomonas aeruginosa & 01 & 0 & 04 & 05 \\
\hline Proteus mirabilis & 0 & 01 & 03 & 04 \\
\hline Nonfermentors & 01 & 01 & 03 & 05 \\
\hline Acinetobacter spps & 0 & 0 & 03 & 03 \\
\hline Enterococcus spps & 0 & 01 & 01 & 02 \\
\hline Candida spps & 0 & 01 & 02 & 03 \\
\hline $\begin{array}{ll}\text { Total } \\
\end{array}$ & 74 & 92 & 146 & 312 \\
\hline
\end{tabular}

* G - Good, A - Average, P - Poor

\section{AUTHORS:}

1. Kalpana Sadawarte

2. Hemant Mahobe

3. Gaurav Saxena

\section{PARTICULARS OF CONTRIBUTORS:}

1. Professor, Department of Microbiology, People's College of Medical Science \& Research Centre, Bhopal, M.P., India.

2. $3^{\text {rd }}$ Year Post Graduate Student, Department of Microbiology, People's College of Medical Science \& Research Centre, Bhopal, M.P., India.

3. $1^{\text {st }}$ Year Post Graduate Student, Department of Microbiology, People's College of Medical Science \& Research Centre, Bhopal, M.P., India.

\section{NAME ADDRESS EMAIL ID OF THE} CORRESPONDING AUTHOR:

Dr. Kalpana Sadawarte, Department of Microbiology, People's College of Medical Science \& Research Centre,

Bhopal, PIN - 462037.

E-mail: drkalpanasadawarte@gmail.com

Date of Submission: 10/01/2014.

Date of Peer Review: 11/01/2014.

Date of Acceptance: 23/01/2014.

Date of Publishing: 04/02/2014. 